\title{
Modifiable Hospital Factors Associated With Survival of Infants Born at Periviable Gestation: the US National Database
}

Ibrahim Qattea ( $\nabla$ dribrahimqattea@gmail.com )

Cleveland Clinic Children's https://orcid.org/0000-0002-6318-6418

\section{Mohsen Farghaly}

Cleveland Clinic Children's

Amani Quatei

Cleveland Clinic Children's

\section{Alshimaa Abdalla}

Cleveland Clinic Children's Hospital

\section{Mohamed Mohamed}

Cleveland Clinic Children's Hospital

\section{Hany Aly}

Cleveland Clinic Children's Hospital https://orcid.org/0000-0001-7395-6394

\section{Article}

Keywords: NICU, Preterm, Survival, Periviable gestation, Perinatal epidemiology

Posted Date: February 1st, 2022

DOI: https://doi.org/10.21203/rs.3.rs-1162917/v1

License: (9) (i) This work is licensed under a Creative Commons Attribution 4.0 International License. Read Full License 


\section{Abstract}

Objective:To determine modifiable hospital factors associated with survival of infants with $G A \leq 24$ weeks and birth weight $<500 \mathrm{gm}$ in the USA. And to assess the trend for the timing of postnatal mortality in these periviable infants.

Design: National data were analyzed for the years 2010-2018. Hospitals were categorized according to delivery volume, US regions, and teaching status.

Results: We identified 33,998,014 infants born during the study period; 76,231 infants were $\leq 24$ weeks. Survival was greatest in urban teaching hospitals in infants $<24$ weeks and completed 24 weeks, respectively. The Northeast region has the lowest survival rate. There was a significant delay in the postnatal day of mortality in periviable infants.

Conclusions: Hospital factors are associated with increased survival rates. Improved survival in large teaching hospitals supports the need for regionalization of care in infants born at the limits of viability. There was a significant delay in the postnatal mortality day.

\section{Introduction:}

Resuscitation of periviable births has considerable medical and ethical challenges. The American Academy of Pediatrics (AAP) Neonatal Resuscitation Program (NRP) recommended to "evaluate the survivability of all preterm infants at birth, regardless of gestational age" and "When gestation, birth weight, or congenital anomalies are associated with almost certain early death and when unacceptably high morbidity is likely among the rare survivors, resuscitation is not indicated."1 The American Academy of Pediatrics and American College of Obstetricians and Gynecologists defined periviable births as those infants born at gestational age (GA) 20 0/7 weeks through 25 6/7 weeks. ${ }^{2}$ Historically, infants born at GA less than 24 weeks were considered non-viable. Consequently, they were not offered resuscitation after birth; ${ }^{3}$ However, these infants were successfully resuscitated at many centers. ${ }^{4}$ The reproducibility of the reported success of periviable infants has not been assessed across the nation.

The survival of periviable gestation varies significantly among various countries and medical centers within the same country. For example, Stoll et al. concluded that among 34,636 premature newborns born at 26 hospitals for the years 1993-2012, survival increased between 2009 and 2012 in infants born at 23 weeks of gestation (from 27-33\%) and in infants born at 24 weeks (from 63-65\%). ${ }^{5}$ Another study from Germany reported survival rates of $22 \%$ and $28 \%$ in infants born at GA of 22 and 23 weeks, respectively. ${ }^{4}$ Another study from thirteen countries within the European Union reported a wide range of survival rates for periviable infants born at 22 weeks (0-37.3\%), 23 weeks (1.1-64.5\%), 24 weeks (31.0-77.7\%), and 25 weeks (59.1-85.7\%). ${ }^{6}$ The variation in survival rate may be attributed to variation in the approach to perinatal care based on different guidelines. ${ }^{6}$ Demographic and biological factors, such as prenatal care and infant sex, are linked to improved survival of premature infants; ${ }^{5}$ however, whether these same 
factors are important for periviable births is unknown. Therefore, there is an unmet need to determine demographic and biological factors associated with increased survival of infants born at periviable GA $\leq$ 24 weeks.

The number of periviable infants constitutes a small fraction of overall births. For example, the rate of premature deliveries $<37$ weeks in the US is around $9.63 \% .^{7}$ of them, $7 \%$ are $<28$ weeks, and only $<1 \%$ are born $\leq 24$ weeks of gestation. ${ }^{8}$ Therefore, the experience of a specific hospital with the resuscitation of periviable infants may significantly vary according to its delivery room volume. Previous studies on rare diseases, such as hypoplastic left heart syndrome, demonstrated a significant improvement in survival when centers have greater exposure to these infants; and it was the volume of cases in the medical center rather than the surgeon experience associated with improved survival. ${ }^{9}$ Whether the delivery room volume would impact survival outcomes in periviable infants is unknown.

This study utilized the National Inpatient Sample (NIS) dataset over nine years (2010 to 2018) to report the survival rate of infants born at GA $\leq 24$ weeks at all hospitals in the USA and assess factors associated with increased survival. In addition, the study aimed to determine trends for a postnatal day of mortality for those who died. We hypothesized that survival is greater in urban teaching hospitals with large delivery services when compared to smaller community-based delivery hospitals, and mortality at the date of birth (day zero) has decreased over time due to a shift in practice with more active resuscitation of periviable infants.

\section{Methods:}

\section{Data sources and management:}

We utilized the de-identified National Inpatient Sample (NIS) dataset from the Healthcare Cost and Utilization Project (HCUP) from the Agency for Healthcare Research and Quality (AHRQ) during the years 2010-2018. HCUP contains the largest collection of hospital discharge data in the United States. The NIS dataset includes $20 \%$ of the HCUP samples weighted to represent $100 \%$ of all inpatients in the US. Each year more than seven million cases are drawn from thousands of hospitals across the United States with various care levels (primary-tertiary), types of insurance (public or private), size of the hospital (small, medium, or large), and many other demographic and clinical characteristics. HCUP used (ICD-9-CM) diagnoses and procedure codes from 2002 to the first nine months of 2015 and (ICD-10-CM) codes from the last three months of 2015 to $2018 .{ }^{10}$ The NIS is designed as a random sample of all US community hospitals from states that contribute their State Inpatient Databases to the HCUP. Data elements in the NIS are constructed in a uniform format with quality checks in place. The NIS data are available from 1988 to 2018, thereby allowing analysis of trends over time. The unweighted data contains more than 7 million hospital stays each year, whereas weighted data estimates more than 35 million hospitalizations nationally. ${ }^{10}$

\section{Study design and population:}


All infants delivered during the study period (2010-2018) were identified. Infants transferred to other facilities were not included to avoid duplication of records. Infants diagnosed with major congenital or chromosomal anomalies were excluded from the study. Infants with GA $\leq 24$ weeks were selected. Survival rates were calculated for two GA categories: $<24$ weeks and completed 24 weeks. Survival rate within each GA category was compared at different hospital settings (urban teaching, urban nonteaching, and rural) and US regions (Northeast, Midwest, South, and West).

Postnatal mortality during each day of the first three days (day 0 , day 1 \& day 2 ) was calculated in each GA category (<24 weeks and completed 24 weeks). It was also determined for infants with birth weight $(B W)<500 \mathrm{~g}$ and for infants with the combined $G A<24$ weeks and $B W<500 \mathrm{~g}$. To assess the impact of the number of annual deliveries on survival, we categorized hospitals in increments of 2000 annual deliveries, thereby yielding five hospital categories with annual deliveries of $\leq 2000,2001-4000,4001$ $6000,6001-8000$, and $>8000$ deliveries/year. We compared survival rates among these five categories after excluding mortalities on day 0 that were presumably related to unviability. Regression analyses were conducted to control for confounding variables. Cochran-Armitage trend test was used to assess trends for mortality in postnatal days 0,1 , and 2 . Significance was considered when the $p$-value was $<0.05$. The study used the weighted data to represent the entire US.

\section{Results:}

The study identified $33,998,014$ infants born during the years 2010 to 2018 . A total of 654,450 infants were excluded from the study due to being transferred or having chromosomal or major congenital anomalies (Figure 1). Among the 33,343,564 included infants, 76,231 infants had GA $\leq 24$ weeks; of them, 34,939 (45.8\%) were females, and 22,834 (30\%) were White. The number of infants $<24$ weeks was 50711 , and those who completed 24 weeks were 25,520 (Figure 1).

Table 1 demonstrates survival rates to hospital demographics. Survival rates were significantly greater in urban teaching hospitals when compared to non-teaching or rural hospitals. The survival rate in infants with $\mathrm{GA}<24$ weeks and infants with completed 24 weeks was greater in urban teaching hospitals. Figure 3 shows the survival rate among the four regions of the US: Northeast, Midwest, South, and West; survival rates were the least in the Northeast region in infants with GA $<24$ weeks $(12.5 \%, 16.5 \%, 18.2 \% \& 14.2 \%$, $p<0.001)$ and in infants with completed 24 weeks $(55.5 \%, 62.2 \%, 61.8 \%, 63.7 \%, p<0.001)$, respectively. 
Table 1

Delivery location and survival rate in infants with gestational age $\leq 24$ weeks $(n=76,231)$

\begin{tabular}{|c|c|c|c|c|c|c|c|}
\hline & & \multicolumn{3}{|c|}{$<24$ weeks GA $(n=50,711)$} & \multicolumn{3}{|c|}{$\begin{array}{l}\text { Completed } 24 \text { weeks GA } \\
(n=25,520)\end{array}$} \\
\hline & & Total & $\begin{array}{l}\text { Alive } \\
(\%)\end{array}$ & $\begin{array}{l}\text { aOR, 95\% } \\
\mathrm{Cl}, \mathrm{P} \text {-value }\end{array}$ & Total & $\begin{array}{l}\text { Alive } \\
(\%)\end{array}$ & $\begin{array}{l}\text { aOR, } 95 \% \\
\mathrm{Cl}, \mathrm{P}- \\
\text { value }\end{array}$ \\
\hline \multirow{3}{*}{$\begin{array}{l}\text { Location/ } \\
\text { teaching status of } \\
\text { hospital }\end{array}$} & Rural & 2258 & $\begin{array}{l}75 \\
(3.3)\end{array}$ & Reference & 345 & $\begin{array}{l}138 \\
(40)\end{array}$ & Reference \\
\hline & $\begin{array}{l}\text { Urban } \\
\text { nonteaching }\end{array}$ & 9352 & $\begin{array}{l}824 \\
(8.8)\end{array}$ & $\begin{array}{l}1.87(1.71- \\
2.04)< \\
0.001\end{array}$ & 2962 & $\begin{array}{l}1654 \\
(55.8)\end{array}$ & $\begin{array}{l}1.59(1.5- \\
1.7)< \\
0.001\end{array}$ \\
\hline & $\begin{array}{l}\text { Urban } \\
\text { teaching }\end{array}$ & 38762 & $\begin{array}{l}7171 \\
(18.5)\end{array}$ & $\begin{array}{l}4.46(4.11- \\
4.84)< \\
0.001\end{array}$ & 22094 & $\begin{array}{l}13820 \\
(62.6)\end{array}$ & $\begin{array}{l}4.03(3.8- \\
4.28)< \\
0.001\end{array}$ \\
\hline \multirow[t]{4}{*}{$\begin{array}{l}\text { Region of the } \\
\text { hospital }\end{array}$} & Northeast & 8740 & $\begin{array}{l}1090 \\
(12.5)\end{array}$ & Reference & 3584 & $\begin{array}{l}1990 \\
(55.5)\end{array}$ & Reference \\
\hline & Midwest & 11677 & $\begin{array}{l}1928 \\
(16.5)\end{array}$ & $\begin{array}{l}1.55(1.48- \\
1.63)< \\
0.001\end{array}$ & 5409 & $\begin{array}{l}3362 \\
(62.2)\end{array}$ & $\begin{array}{l}1.4(1.35- \\
1.45)< \\
0.001\end{array}$ \\
\hline & South & 19642 & $\begin{array}{l}3576 \\
(18.2)\end{array}$ & $\begin{array}{l}1.65(1.58- \\
1.74)< \\
0.001\end{array}$ & 11214 & $\begin{array}{l}6928 \\
(61.8)\end{array}$ & $\begin{array}{l}1.66(1.6- \\
1.72)< \\
0.001\end{array}$ \\
\hline & West & 10653 & $\begin{array}{l}1515 \\
(14.2)\end{array}$ & $\begin{array}{l}1.06(1- \\
1.11) \\
0.049\end{array}$ & 5313 & $\begin{array}{l}3387 \\
(63.7)\end{array}$ & $\begin{array}{l}1.24 \\
(1.19- \\
1.29)< \\
0.001\end{array}$ \\
\hline \multirow{3}{*}{$\begin{array}{l}\text { Control/ } \\
\text { ownership of } \\
\text { hospital }\end{array}$} & $\begin{array}{l}\text { Government, } \\
\text { nonfederal }\end{array}$ & 6394 & $\begin{array}{l}1204 \\
(18.8)\end{array}$ & Reference & 3623 & $\begin{array}{l}2212 \\
(61.1)\end{array}$ & Reference \\
\hline & $\begin{array}{l}\text { Private, not- } \\
\text { profit }\end{array}$ & 38506 & $\begin{array}{l}5989 \\
(15.6)\end{array}$ & $\begin{array}{l}0.83(0.79- \\
0.87)< \\
0.001\end{array}$ & 19326 & $\begin{array}{l}11989 \\
(62)\end{array}$ & $\begin{array}{l}0.88 \\
(0.85- \\
0.91)< \\
0.001\end{array}$ \\
\hline & $\begin{array}{l}\text { Private, } \\
\text { invest-own }\end{array}$ & 5472 & $\begin{array}{l}876 \\
(16)\end{array}$ & $\begin{array}{l}0.94(0.89- \\
\text { 1) } 0.045\end{array}$ & 2452 & $\begin{array}{l}1411 \\
(57.5)\end{array}$ & $\begin{array}{l}0.77 \\
(0.73- \\
0.80)< \\
0.001\end{array}$ \\
\hline
\end{tabular}

There were incremental increases in survival rates in medical centers with larger delivery services, Table 2. The effect of annual delivery volume was most observed in infants with a combined GA<24 weeks and 
$\mathrm{BW}<500$, wherein survival ranged from $13.7-22.4 \%$ in medical centers with annual deliveries of $\leq 2000$ and $>8000$, respectively.

Table 2

Hospital delivery volume and the survival rate of infants with gestational age $<24$ weeks GA and birthweight $<500$ grams

\begin{tabular}{|c|c|c|c|c|c|c|}
\hline \multirow[t]{2}{*}{$\begin{array}{l}\text { Delivery number } \\
\text { per year }\end{array}$} & \multicolumn{2}{|c|}{$<24$ weeks } & \multicolumn{2}{|c|}{$<500 \mathrm{gm}$} & \multicolumn{2}{|c|}{$\begin{array}{l}<24 \text { weeks and }<500 \\
\text { gm }\end{array}$} \\
\hline & (\%) & $\begin{array}{l}\text { aOR, } 95 \% \mathrm{Cl}, \mathrm{P}- \\
\text { value }\end{array}$ & $(\%)$ & $\begin{array}{l}\text { aOR, } 95 \% \mathrm{Cl}, \mathrm{P}- \\
\text { value }\end{array}$ & (\%) & $\begin{array}{l}\text { aOR, } 95 \% \mathrm{Cl} \text {, } \\
\text { P-value }\end{array}$ \\
\hline$\leq 2000$ & 22 & Reference & 19.1 & Reference & 13.7 & Reference \\
\hline $2001-4000$ & 23.5 & $\begin{array}{l}1.07(1.04-1.09)< \\
0.001\end{array}$ & 25.8 & $\begin{array}{l}1.35(1.31-1.44) \\
<0.001\end{array}$ & 17.5 & $\begin{array}{l}1.27(1.11- \\
1.34)<0.001\end{array}$ \\
\hline $4001-6000$ & 24.7 & $\begin{array}{l}1.12(1.09-1.18)< \\
0.001\end{array}$ & 28 & $\begin{array}{l}1.47(1.4-1.54)< \\
0.001\end{array}$ & 17.6 & $\begin{array}{l}1.28(1.13- \\
1.36)<0.001\end{array}$ \\
\hline $6001-8000$ & 26.6 & $\begin{array}{l}1.22(1.17-1.31)< \\
0.001\end{array}$ & 30.2 & $\begin{array}{l}1.58(1.49-1.64) \\
<0.001\end{array}$ & 18.1 & $\begin{array}{l}1.32(1.21- \\
1.44)<0.001\end{array}$ \\
\hline$>8000$ & 26.9 & $\begin{array}{l}1.23(1.18-1.33)< \\
0.001\end{array}$ & 30 & $\begin{array}{l}1.57(1.41-1.74) \\
<0.001\end{array}$ & 22.4 & $\begin{array}{l}1.63(1.52- \\
1.75)<0.001\end{array}$ \\
\hline
\end{tabular}

Postnatal mortalities in infants $<24$ weeks during the first three days were $59.1 \%, 31.5 \%$, and $8.2 \%$ on days of life 0,1 , and 2 , respectively. For infants with BW $<500 \mathrm{~g}$, postnatal mortalities were $66 \%, 36.8 \%$, and $9.6 \%$ on days of life 0,1 , and 2 , respectively. For infants with combined GA $<24$ weeks and $B W<500 \mathrm{~g}$, postnatal mortalities $76 \%, 59 \%$, and $12.6 \%$ on days of life 0,1 , and 2 , respectively.

There was a significant trend for decreasing mortality on day 0 (from 66.1 to $55.5 \%$ ) and day 1 (from 34$30.9 \%$ ) and increasing mortality on day 2 (from 8.4-10.1\%) in infants with GA $<24$ weeks. The infants born with $\mathrm{BW}<500 \mathrm{~g}$ and combined $\mathrm{GA}<24$ weeks and $\mathrm{BW}<500 \mathrm{~g}$ showed a trend for decreasing mortality on day 0 only (Figure 2 ).

\section{Discussion:}

This study utilized data on 33,998,014 infants to report the national survival trends of periviable infants with $\mathrm{GA} \leq 24$ weeks and $\mathrm{BW}<500 \mathrm{~g}$. Modifiable factors associated with improved survival were delivery at urban teaching hospitals and hospitals with high delivery volumes. Survival of periviable infants was the least in the Northeast region. For infants who died, there was a significant delay in the postnatal day of mortality over the years as mortality at postnatal day 0 has decreased significantly. 
The survival of periviable infants with $\mathrm{GA} \leq 24$ weeks was greater in urban teaching hospitals. This novel finding aligns with previous studies conducted on very low birth weight infants that demonstrated improved survival, up to three folds, in tertiary care perinatal centers staffed with subspecialty teams. The less mortality at tertiary centers is explained by the significant experience attributed to high volume, the emphasis on education and quality improvement, and the consistent implementation of updated guidelines. ${ }^{11,12}$

The Northeast region had the least survival rate for periviable infants. In infants with GA $<24$ weeks, there was an almost $50 \%$ increase in survival between the Northeast and the South regions ( $12.5 \%$ vs. $18.2 \%)$. However, for infants with completed 24 weeks of gestation, disparities in survival rates in different regions were nominal; the West region had the highest survival rate (63.7\%), whereas the Northeast region had the least survival rate of $55.5 \%$. Regional survival variability is likely attributed to differences in proactive interventions and resuscitations offered to periviable infants in various US regions. It is unclear why the Northeast region is less proactive in rescuing periviable infants, although there are possibilities to explain this phenomenon. Maternal characteristics are known to influence the decision to resuscitate periviable infants. A previous study demonstrated a regional difference in interventions for periviable infants; Midwest and South regions are more likely to administer prenatal steroids, perform cesarean delivery, and resuscitate infants at delivery when compared to Northeast and West regions. ${ }^{13}$

Nonetheless, caregivers' and institutions' norms are shown to be more influential on decisions to resuscitate periviable infants. ${ }^{13}$ Previous studies demonstrated discordance among providers regarding their preferred actions to 23 and 22 weeks of gestation deliveries. ${ }^{14}$ Therefore, the current study illustrates the need to have system-based interventions to ensure equity of care provided to periviable infants. Guidelines for handling and resuscitating periviable infants are required to eliminate the significant variation in practice across the nation.

There was an incremental increase in survival rates in hospitals with greater delivery volumes. In infants with $\mathrm{GA}<24$ weeks and infants with $\mathrm{BW}<500 \mathrm{~g}$, the survival rate was noted to be increased with increasing annual deliveries up to 6000 . However, for infants with combined $\mathrm{GA}<24$ weeks and BW<500g, the highest survival rate was achieved in centers with annual deliveries $>8000$. The finding in this study supports the call for regionalization of care as referral centers with the highest delivery volumes tend to have the expertise and facilities to care for these infants. Previous studies demonstrated the positive impact of high volume on the survival of infants with different pathologies, including certain congenital heart disease and congenital diaphragmatic hernia. ${ }^{9,15}$

The majority of mortality in periviable infants occurs within the first three days of life (day 0 - day 2). Mortality in the first 24 hours (day 0 ) constitutes the main bulk of all mortalities. The study reported a significant trend for decreasing mortality on day 0 over the years, from $66.1 \%$ in 2010 to $51.4 \%$ in 2018 . The decreased mortality on days 0 and 1, despite a known increase in the resuscitation of periviable infants, ${ }^{16,17}$ reflects a significant improvement in experience and care provided to periviable infants. On the other hand, more non-viable infants are presently surviving through days 0 and 1 , leading to 
significantly increased mortalities from $8.4-10.1 \%$ during day two of life. Therefore, it is wise for a caregiver to be conservative about survival estimates when counseling families during the first three days of life.

A strength of this study is that it included all deliveries in the US, thereby representing the entire nation without biases associated with the selection of major urban or academic centers. ${ }^{18}$ The study included multiple years; consequently national trend for the survival of periviable infants was accurately estimated. This administrative database depends on ICD-9 and ICD-10 coding for diagnoses. Therefore, errors related to death and survival are almost impossible. One of the limitations of this study is the lack of detailed information on clinical presentation, risk factors, and interventions of periviable infants. Furthermore, the HCUP provides only an inpatient dataset; therefore, the long-term neurodevelopmental outcome of periviable infants was not reported in this study.

In summary, the survival rate for infants at the limit of viability has significantly increased during the period 2010-2018. The Northeast region had the lowest survival rate in the US. In addition to the US region, other modifiable factors that influenced the survival of periviable infants were the volume of delivery and the hospital's teaching status. The study supports the need for regionalization of care in infants born at the limits of viability and the need to establish clear guidelines for managing periviable infants to eliminate health disparities.

\section{Declarations:}

\section{Conflict of Interest Disclosures:}

All authors claim no financial interest related to this research.

\section{Funding/Support:}

None.

\section{Contributors' Statement Page:}

Ibrahim Qattea, MD, conceptualized and designed the study, conducted the analysis, drafted the initial manuscript, and reviewed the manuscript.

Mohsen A.A. Farghaly, MD, drafted the initial manuscript and reviewed the manuscript.

Alshimaa Abdalla, MD, and Amani Quatei, MD, drafted the initial manuscript and reviewed the manuscript.

Mohamed A Mohamed, MD, critically revised the manuscript and statistical analyses and approved the final draft of the manuscript. 
Hany Aly, MD, conceptualized and designed the study, interpreted the analysis, drafted the initial manuscript, and reviewed and revised the manuscript.

\section{References:}

1. American Heart Association. 2005 American Heart Association (AHA) guidelines for cardiopulmonary resuscitation (CPR) and emergency cardiovascular care (ECC) of pediatric and neonatal patients: pediatric basic life support. Pediatrics. 2006;117(5):e989-1004. doi:10.1542/peds.2006-0219

2. Ecker JL, Kaimal A, Mercer BM, et al. \#3: Periviable birth. Am J Obstet Gynecol. 2015;213(5):604-614. doi:10.1016/j.ajog.2015.08.035

3. Kelly K, Meaney S, Leitao S, O'Donoghue K. A review of stillbirth definitions: A rationale for change. Eur J Obstet Gynecol Reprod Biol. 2021;256:235-245. doi:10.1016/j.ejogrb.2020.11.015

4. Mehler K, Oberthuer A, Keller T, et al. Survival among infants born at 22 or 23 weeks' gestation following active prenatal and postnatal care. JAMA Pediatr. 2016;170(7):671-677. doi:10.1001/jamapediatrics.2016.0207

5. Stoll BJ, Hansen NI, Bell EF, et al. Trends in care practices, morbidity, and mortality of extremely preterm neonates, 1993-2012. JAMA. 2015;314(10):1039-1051. doi:10.1001/jama.2015.10244

6. Patel RM, Rysavy MA, Bell EF, Tyson JE. Survival of infants born at periviable gestational ages. Clin Perinatol. 2017;44(2):287-303. doi:10.1016/j.clp.2017.01.009

7. Martin JA, Hamilton BE, Osterman MJK, Driscoll AK, Mathews TJ. Births: final data for 2015. Natl Vital Stat Rep Cent Dis Control Prev Natl Cent Health Stat Natl Vital Stat Syst. 2017;66(1):1.

8. Martin JA, Hamilton BE, Osterman MJ, Curtin SC, Matthews TJ. Births: final data for 2013. Nat/ Vital Stat Rep Cent Dis Control Prev Natl Cent Health Stat Natl Vital Stat Syst. 2015;64(1):1-65.

9. Checchia PA, McCollegan J, Daher N, Kolovos N, Levy F, Markovitz B. The effect of surgical case volume on outcome after the Norwood procedure. J Thorac Cardiovasc Surg. 2005;129(4):754-759. doi:10.1016/j.jtcvs.2004.07.056

10. Coffey R, Barrett M, Levit K. Population denominator data for usewith thr HCUP databases. :45.

11. Phibbs CS, Baker LC, Caughey AB, Danielsen B, Schmitt SK, Phibbs RH. Level and volume of neonatal intensive care and mortality in very-low-birth-weight infants. N Engl J Med. 2007;356(21):2165-2175. doi:10.1056/NEJMsa065029

12. Binder S, Hill K, Meinzen-Derr J, Greenberg JM, Narendran V. Increasing VLBW Deliveries at Subspecialty Perinatal Centers via Perinatal Outreach. Pediatrics. 2011;127(3):487-493. doi:10.1542/peds.2010-1064

13. McKenzie F, Robinson BK, Tucker Edmonds B. Do maternal characteristics influence maternal-fetal medicine physicians' willingness to intervene when managing periviable deliveries? J Perinatol Off $J$ Calif Perinat Assoc. 2016;36(7):522-528. doi:10.1038/jp.2016.15

14. Arbour K, Lindsay $E$, Laventhal $N$, et al. Shifting provider attitudes and institutional resources surrounding resuscitation at the limit of gestational viability. Am J Perinatol. Published online 
October 27, 2020. doi:10.1055/s-0040-1719071

15. Bartels DB, Wypij D, Wenzlaff P, Dammann O, Poets CF. Hospital Volume and Neonatal Mortality Among Very Low Birth Weight Infants. Pediatrics. 2006;117(6):2206-2214. doi:10.1542/peds.20051624

16. Mercer BM. Periviable birth and the shifting limit of viability. Clin Perinatol. 2017;44(2):283-286. doi:10.1016/j.clp.2017.02.002

17. Ishii N, Kono Y, Yonemoto N, Kusuda S, Fujimura M, Neonatal Research Network, Japan. Outcomes of infants born at 22 and 23 weeks' gestation. Pediatrics. 2013;132(1):62-71. doi:10.1542/peds.20122857

18. Younge N, Goldstein RF, Bann CM, et al. Survival and neurodevelopmental outcomes among periviable infants. N Engl J Med. 2017;376(7):617-628. doi:10.1056/NEJMoa1605566

\section{Figures}

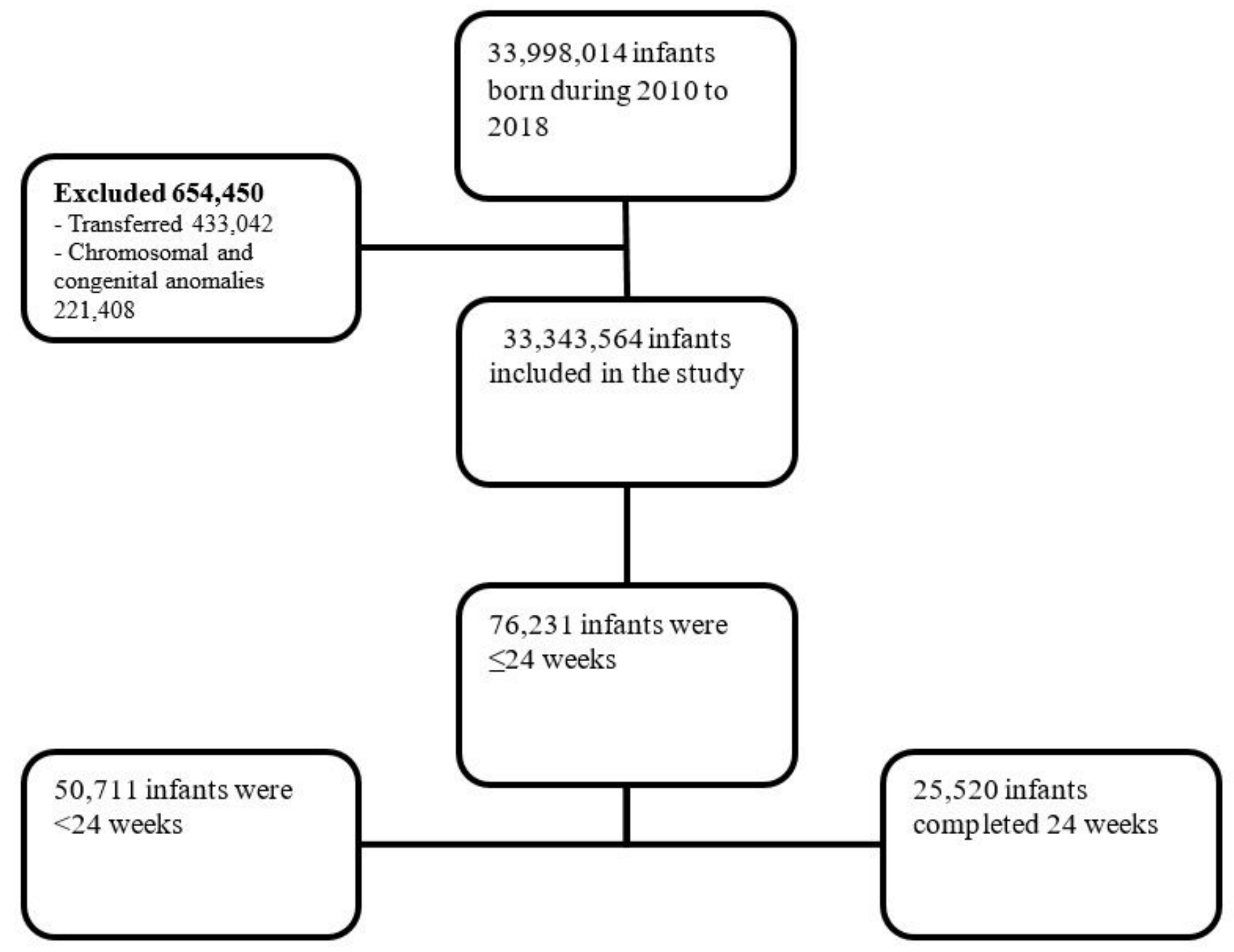


Figure 1

Study population
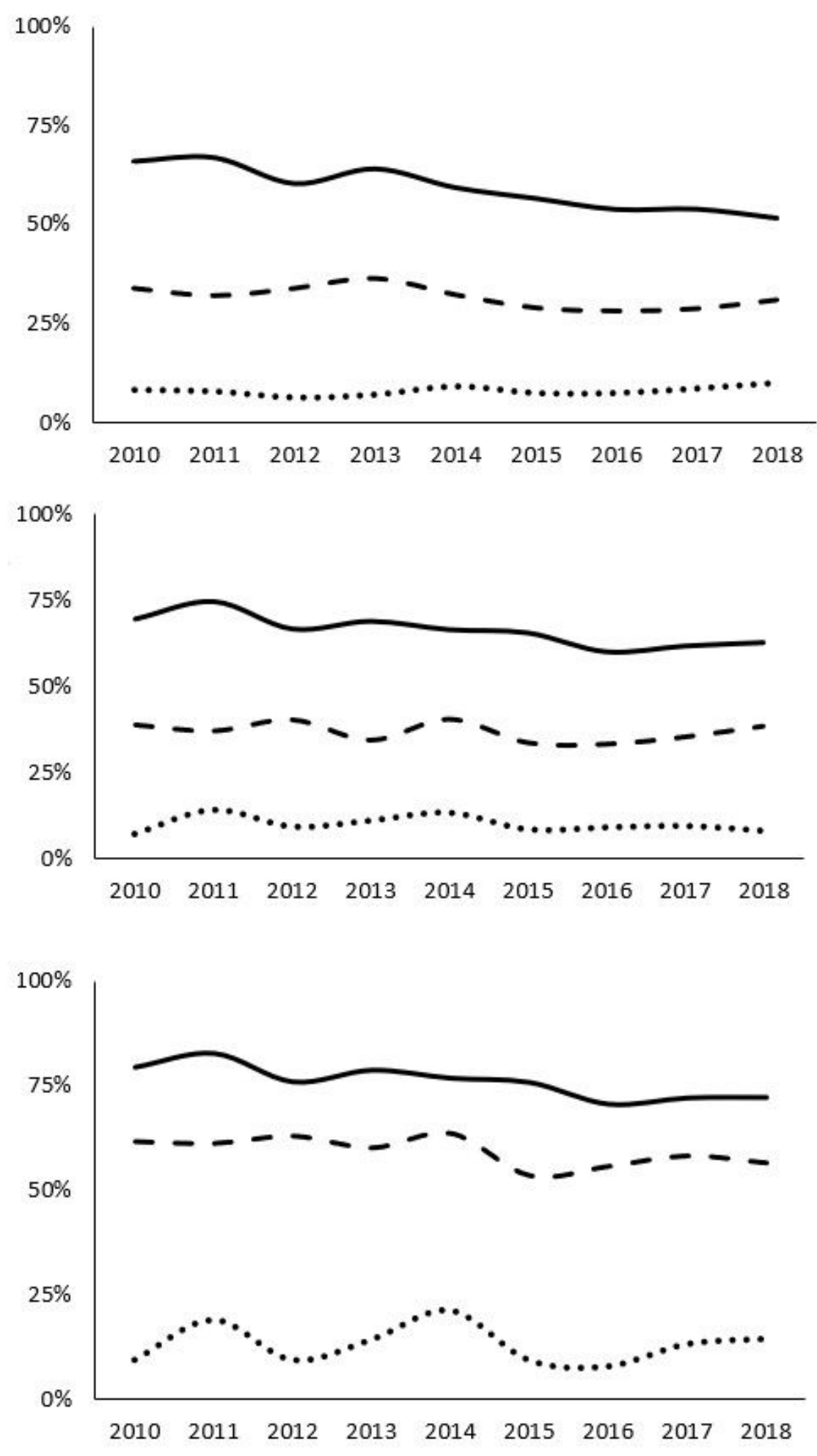

Figure 2

Trends for postnatal mortality of periviable infants during the first three days 
-The upper panel represents postnatal mortality trends in infants with gestational age <than 24 weeks based on length of stay, The solid line represents mortality trend (\%) at the day of life 0 , the dashed line represents mortality trend (\%) at the day of life 1, and the dotted line represents mortality trend (\%) at the day of life 2 . There was a significant decrease in mortality at day $0(Z=-10.30, P<0.001)$ and day 1 $(Z=-3.747, P<0.001)$ and increase mortality at day $2(Z=2.80, P 0.005)$.

-The middle panel represents postnatal mortality trends in infants with birthweight $<500 \mathrm{~g}$ based on length of stay. The solid line represents mortality trend (\%) at day 0 , the dashed line represents mortality trend $(\%)$ at day 1 , and the dotted line represents mortality trend (\%) at day 2 . There was a significant decrease in mortality at day $0(Z=-5.72, P<0.001)$ and a significant increase in mortality at day $2(Z=3.07$, $P$ 0.002). Mortality on day one did not change $(Z=1.04, P 0.29)$.

-The lower panel represents mortality trends in infants with combined gestational age $<24$ weeks and birthweight $<500 \mathrm{~g}$. The solid line represents mortality trend $(\%)$ at day 0 , the dashed line represents mortality trend (\%) at day 1 , and the dotted line represents mortality trend (\%) at day 2 . There was a significant decrease in mortality at day $0(Z=-4.13, P<0.001)$ without change in mortality at day $1(Z=1.64$, $P 0.074)$ and day $2(Z=1.08, P 0.27)$. 

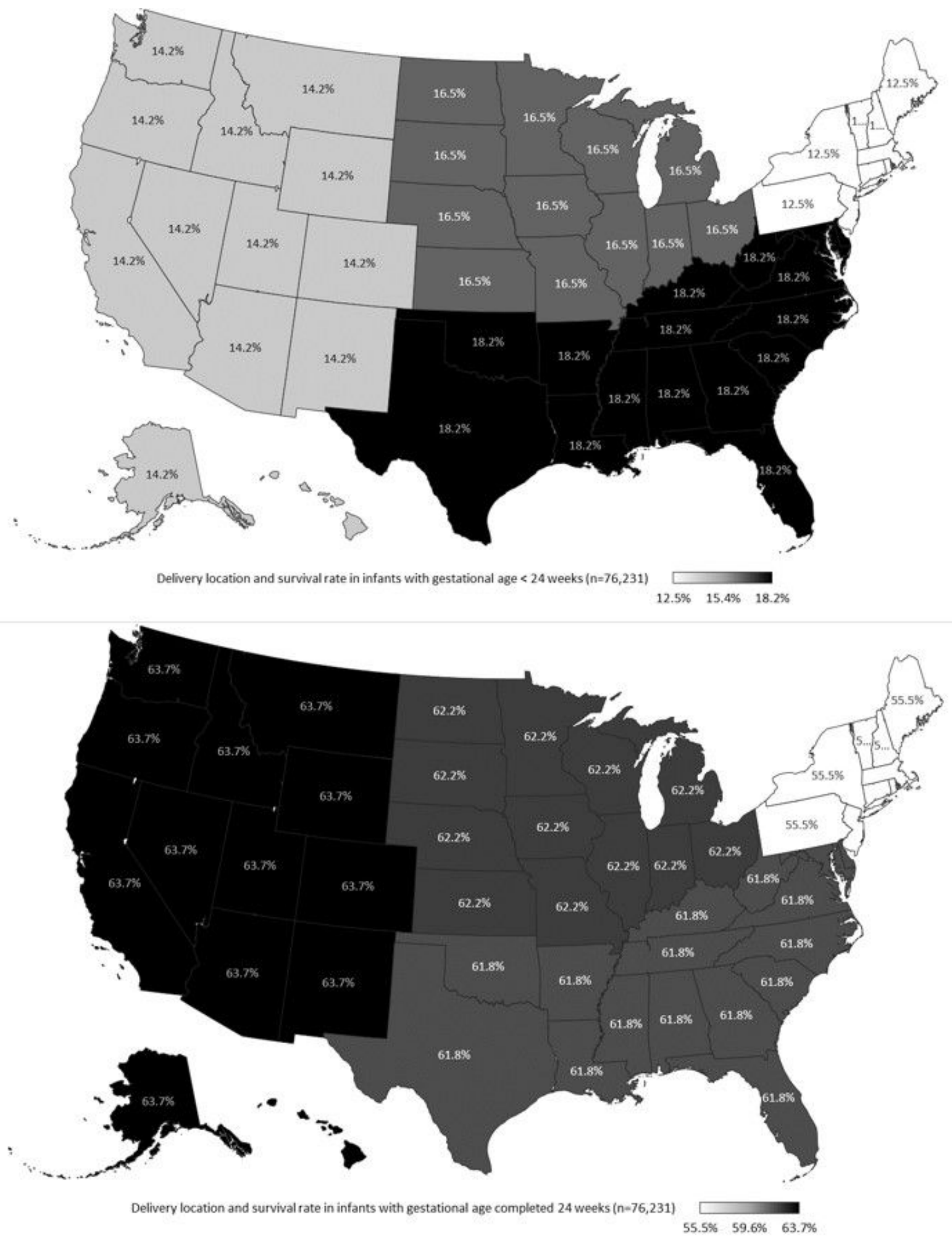

\section{Figure 3}

Regional distribution of survival in periviable infants

-The upper map demonstrates survival distribution in infants with gestational age $<24$ weeks.

-The lower map demonstrates survival distribution infants with completed 24 weeks of gestation. 
-The Northeast region has the lowest survival rate in both maps. 